\title{
Surgical correction of a spinal arteriovenous fistula with an unusual presentation
}

\author{
Aaron Cohen-Gadol, M.D., M.Sc. \\ Goodman Campbell Brain and Spine \& Indiana University Department of Neurological Surgery, \\ Indianapolis, IN
}

Spinal dural arteriovenous fistula (dAVF) is an acquired abnormal arterial-to-venous connection within the spinal dura with a wide range of clinical presentations and natural history. Spinal dAVF occurs when a radicular artery makes a direct anomalous shunt with a radicular vein within the dura of the nerve root sleeve. Cervical dAVF is a rare entity as the majority of spinal dAVFs present within the thoracolumbar segment with myelopathy. Only a small number of cervical lesions have been described, and only one presented with brainstem dysfunction.

Herein we present one patient with brainstem dysfunction secondary to a spinal dAVF. The fistula was located within the C-3 nerve root sleeve. The details of microsurgical techniques to disconnect the fistula will be discussed. Although the option of endovascular disconnection of the fistula is reasonable, the author elected to proceed with microsurgical disconnection after discussion regarding the risks of such an endovascular route for the cervical spinal cord.

The video can be found here: http://youtu.be/t8rUnZ8qVfY.

(http://thejns.org/doi/abs/10.3171/2012.V2.FOCUS12145)

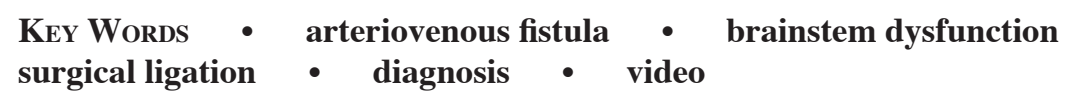

Manuscript submitted April 29, 2012

Accepted May 17, 2012.

Please include this information when citing this paper: DOI:

10.3171/2012.V2.FOCUS12145.

Address correspondence to: Aaron A Cohen-Gadol, MD, MSc, Goodman Campbell Brain and Spine, Indiana University Department of Neurological Surgery, 1801 N Senate Blvd \#610, Indianapolis, IN 46202. email: acohenmd@gmail.com. 